\title{
Nuclear localization of DEDD leads to caspase- 6 activation through its death effector domain and inhibition of RNA polymerase I dependent transcription
}

\author{
O Schickling ${ }^{1}$, AH Stegh ${ }^{1}$, J Byrd ${ }^{1}$ and ME Peter ${ }^{*, 1}$ \\ 1 The Ben May Institute for Cancer Research, University of Chicago, 924 E 57th \\ Street, Chicago, Illinois, IL 60637, USA \\ * Corresponding author: ME Peter. Tel: 773-702-4728; Fax: 773-702-3701; \\ E-mail: MPeter@ben-may.bsd.uchicago.edu
}

Received 16.5.01; revised 3.7.01; accepted 4.7.01

Edited by S Kumar

\begin{abstract}
The death effector domain (DED) is a protein/protein interaction domain only found in proteins that are involved in apoptosis signaling. DEDD is a novel apoptosis signaling molecule that carries an N-terminal DED with complete sequence identity between the murine, rat, bovine and human domains. We previously identified two nuclear localization signals (NLS) responsible for DEDDs nuclear localization when transiently expressed. Using a new antiDEDD antibody that allows us to stain endogenous DEDD in immunofluorescence microscopy we now detect a significant amount of DEDD in nucleoli of all cells tested. When overexpressed, DEDD localizes to nucleoli-like structures, activates caspase- 6 and specifically inhibits RNA polymerase I (Pol I) dependent transcription in vivo as shown by blockage of BrUTP incorporation. The DED in DEDD is sufficient for its DNA binding, caspase- 6 activating and Pol I specific transcriptional repressor activity. We have identified a third NLS in DEDD and only mutation of all three NLS generated a protein, DEDD $\Delta$ NLS1-3, that mainly localized to the cytoplasm. This protein no longer induced apoptosis, indicating that in contrast to other DED proteins, such as FADD, caspase-8 or c-FLIP, DEDD induces apoptosis from within the nucleus. This effect is abolished when specific point mutations are made within the DED. The DED in DEDD therefore represents a novel domain that is structurally similar to other DEDs but functionally different from classical DEDs found in FADD or caspase-8. Cell Death and Differentiation (2001) 8, 1157-1168.
\end{abstract}

Keywords: apoptosis; caspase-6; DEDD; nucleolus; rDNA transcription

Abbreviations: DED, death effector domain; DEDD, DED containing DNA binding protein; UBF, upstream binding factor; NLS, nuclear translocation signal; GFP, green fluorescent protein; Pol, polymerase

\section{Introduction}

Apoptosis, or programmed cell death, is a process which eliminates cells in response to a wide range of stimuli, such as death ligands (e.g. CD95 ligand, tumor necrosis factor or TRAIL), anti-cancer drugs, UV radiation, or growth factor deprivation. ${ }^{1-3}$ Cells undergoing apoptosis show a sequence of cardinal morphological features, including membrane blebbing, cellular shrinkage and condensation and fragmentation of the nuclei. ${ }^{4-6} \mathrm{~A}$ number of events can be detected between the early morphological and nuclear changes in apoptosis, depending on the type of apoptosis and the cell tested. Death effector domain (DED) containing proteins have been shown to play an obligate role in death receptor mediated apoptosis. ${ }^{3}$ The binding of the DED protein caspase-8 to the death-inducing signaling complex (DISC) of CD95 (APO-1/Fas) results in its activation, mediated by the adapter molecule FADD (also called Mort-1). FADD contains a DED that interacts with the N-terminal DED in caspase-8. ${ }^{7-11}$ The involvement of other DED containing proteins in signaling of death receptors has been shown, including caspase-10 (Mch4/ FLICE2), ${ }^{12,13}$ c-FLIP (FLAME/CASH/I-FLICE/Casper/Mrit/ Clarp/Usurpin $)^{14,15}$ and PEA-15/PED. ${ }^{16}$ DED proteins can also induce apoptosis independently of death receptors. $^{17-19}$ The cytotoxic capacity of DED proteins has been demonstrated in overexpression experiments, where the DED proteins form death effector filaments that engage the cytoplasmic apoptosis machinery. ${ }^{20,21}$ It was even recently shown that when expressed in bacteria, which do not have caspases, FADD induces cell death ${ }^{22}$ suggesting that DED proteins can do more than simply engage the caspase-8 dependent apoptosis machinery. We have recently identified a novel multi-domain DED-containing protein, DEDD, that resides in the cytoplasm but localizes to the nucleus when overexpressed, likely by way of its two nuclear localization signals. ${ }^{23}$ Despite a homology of DEDD's DED, which is similar to the homology between the DED of FADD and caspase-8, DEDD cannot associate with the DISC. Only a weak association between DEDD and cytoplasmic FADD could be detected late after induction of apoptosis. ${ }^{23}$ We now show that DEDD contains a third NLS in its N-terminal domain. In contrast to all other DED proteins DEDD is cytotoxic when overexpressed from within the nucleus and a functional DED is required to engage a nuclear apoptosis machinery that results in activation of caspase-6. Active caspase-6 colocalized with DEDD in nucleoli. Independently of caspase activation, DEDD specifically inhibits rDNA transcription in nucleoli through its DED. Together with detection of endogenous DEDD in nucleoli the data suggest an in vivo role for DEDD in nucleoli. 


\section{Results}

\section{Identification of a third NLS within DEDD}

Using chromosomal clones, we mapped the gene for dedd to human chromosome 1q21.2-21.3 and the distal band G-H on mouse chromosome 1 . This region has been shown to be a site of frequent chromosome abnormalities in a number of human cancers, such as breast carcinomas. ${ }^{24}$ We have determined the exon/intron structure of murine and human dedd (Figure 1A) and fully sequenced both loci. The genes
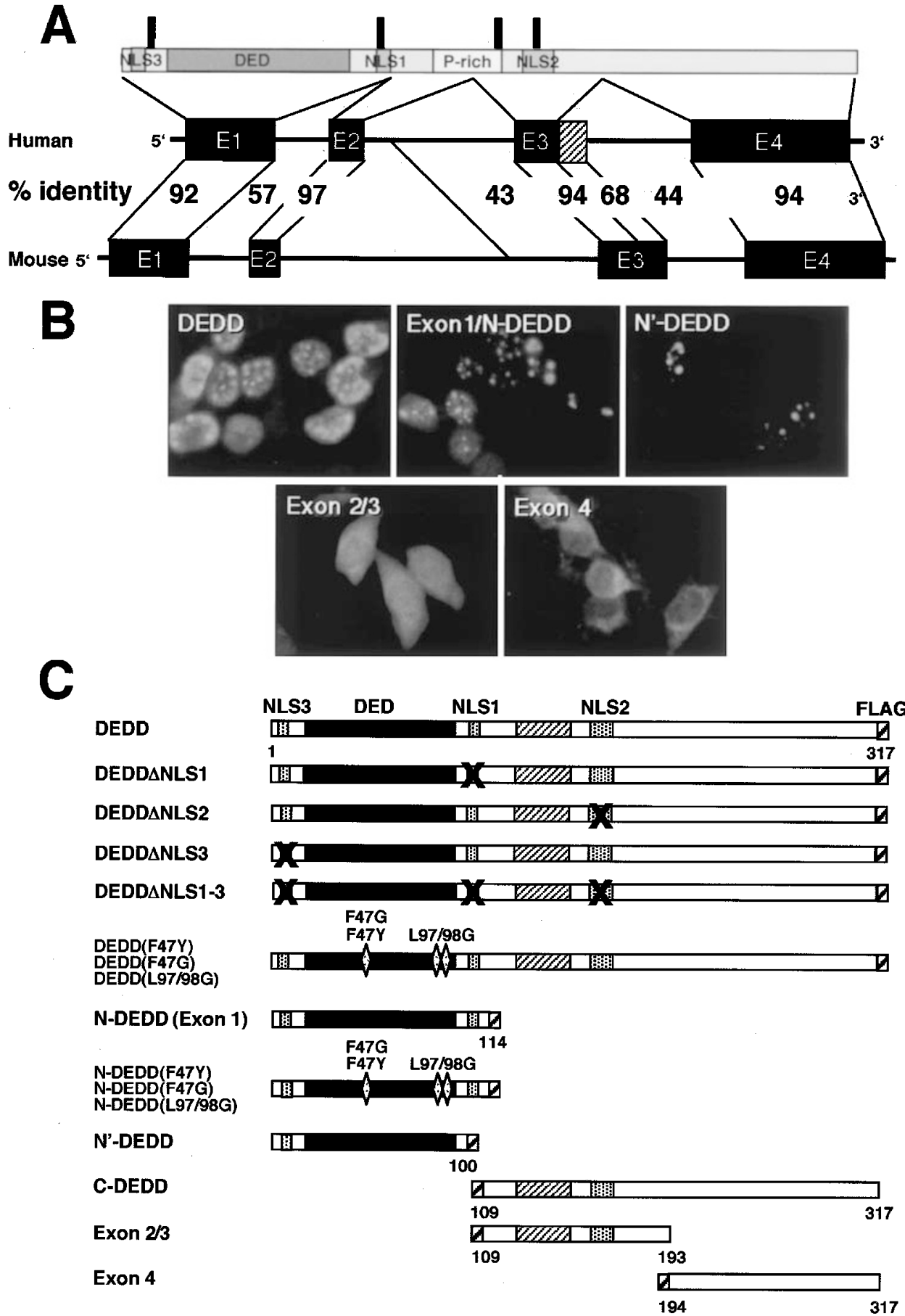

Figure 1 Identification of a third NLS in DEDD. (A) Comparison of the exon/intron structure of human and mouse dedd. The degree of identity on the nucleotide level between the two species is given. Sites of single amino acid exchanges are shown as vertical black bars. The hatched part of intron three in human dedd can be part of exon 2 due to differential splicing. (B) Localization of FLAG tagged domains of DEDD in transiently transfected 293T cells. N'-DEDD (amino acids 1-98) corresponds to N-DEDD lacking the C-terminal 16 amino acids containing NLS1. (C) Schematic representation of all DEDD mutants used in this study. The predicted molecular weight of the constructs are: DEDD; $37 \mathrm{kDa}$; N-DEDD, $13.5 \mathrm{kDa}$; N'-DEDD, $11.8 \mathrm{kDa}$; C-DEDD, 23.9 kDa; Exon 2/3, 9.5 kDa; Exon 4, 14.5 kDa. All constructs carry an additional FLAG tag at the indicated position (hatched box) 
are relatively small, spanning only $2.9 \mathrm{~kb}$ in mouse and $2.3 \mathrm{~kb}$ in human. Both mouse and human DEDD proteins are coded by 4 exons, the first exon coding for the recently identified nuclear localization signal (NLS) 3 (see below) the DED and NLS1. Exons 2 and 3 code for the proline-rich region and the second NLS, and exon 4 for the C-terminal domain that has homology to histone proteins. ${ }^{23}$ When the full genomic sequences of both genes were subjected to exon/intron prediction analysis, mouse exon 3 was found to be $102 \mathrm{bp}$ longer than human exon 3 , but still linked to the same exon 4 as the human gene. The resulting mouse protein has therefore a predicted size of 355 amino acids whereas human DEDD is predicted to be 317 amino acids. A 951 bp DEDD cDNA was originally amplified from both human Jurkat and murine EL4 cells using the same flanking primers, ${ }^{23}$ suggesting expression of different DEDD splice forms. We also found that murine DEDD in EL-4 cells migrated as a $40 \mathrm{kDa}$ protein in Western blot, consistent with a protein $4 \mathrm{kDa}$ longer in mice than in humans (data not shown). However, the longer splice form was also detected in peripheral human T cells by RT-PCR (data not shown), indicating that in both human and mouse cells, DEDD, as with many other apoptosis signaling molecules, exists in alternatively spliced forms that may be expressed in a tissue specific fashion.

We have recently reported that transiently overexpressed DEDD efficiently localized to nuclei. ${ }^{23} \mathrm{We}$ identified two putative NLS in DEDD, suggesting that DEDD translocates to the nucleus by a classical mechanism. Since exons often code for functional domains we generated DEDD truncation mutants corresponding to exon 1 (=N-DEDD), exon $2 / 3$ and exon 4 (see Figure $1 A, C)$ and determined their intracellular localization (Figure 1B). This approach also enabled us to determine the contribution of each individual NLS to the nuclear localization of DEDD. The exon 2/3 construct was found in both the nucleus and cytoplasm and the exon 4 construct was purely cytoplasmic. Similar to full length DEDD, NDEDD translocated to the nucleus and formed nucleoli-like structures, which were even more pronounced than those formed by full-length DEDD. Surprisingly, N'-DEDD (N-
DEDD lacking the region that includes NLS1) translocated to these structures still more efficiently, suggesting that DEDD contained at least one other unidentified NLS within its N-terminal 100 amino acids. To exclude the possibility that this molecule entered the nucleus passively due to its small size we generated a GFP fusion protein of $\mathrm{N}^{\prime}$-DEDD. GFP-N'-DEDD effectively translocated to the nucleus indicating that $\mathrm{N}^{\prime}$-DEDD contains sequences that direct it to the nucleus (data not shown). A third NLS (NLS3) was then identified as a Lys-Arg-Arg motif in the region preceding the DED (positions 3-7).

\section{DEDD requires a nuclear localization to be proapoptotic}

We recently showed that DEDD weakly induced apoptosis and that this apoptosis inducing activity likely involved the DED. ${ }^{23}$ This result was expected, because other DED containing proteins such as FADD, caspase-8 and c-FLIP have also been shown to induce apoptosis through their DED upon overexpression., ${ }^{8,25}$ All of these proteins are expressed in the cytoplasm and it has been suggested that overexpression of DED containing proteins results in formation of so called death effector filaments that may recruit and activate caspase- 8 in the cytosol. ${ }^{20} \mathrm{We}$ therefore assumed that DEDD would induce apoptosis by a similar mechanism. However, in contrast to other DED containing proteins DEDD cannot be detected in the cytoplasm when transiently expressed in 293T cells. If DEDD induced apoptosis in the cytoplasm, mutating its three NLS should generate a cytosolic protein that would be more cytotoxic than wild type DEDD. To test this, we deleted all three NLS using site directed mutagenesis. Only deletion of all three NLS resulted in a protein that was expressed exclusively in the cytosol (Figure 2A). This construct was no longer cytotoxic however, indicating that a nuclear localization of DEDD was necessary to induce apoptosis (Figure 2B). Deletion of any of the NLS individually resulted in a protein which enriched in subnuclear structures indicating both that all three NLS are active and that none of the NLS was responsible for apoptosis reduction. The subcellular localization of DEDD was con-
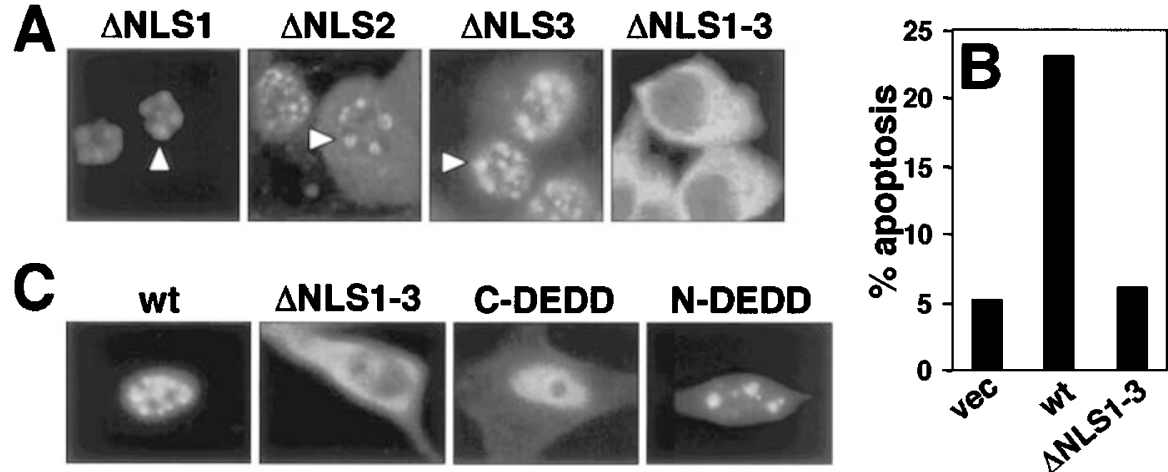

Figure 2 DEDD requires a nuclear localization to be proapoptotic. (A) Localization of FLAG tagged DEDD NLS mutants in transiently transfected 293T cells Arrows point to subnuclear structures that are enriched in transfected DEDD. (B) The degree of DNA fragmentation in 293T cells transiently transfected with DEDD or DEDD without a functional NLS ( $\triangle$ NLS1-3). The experiment shown is representative of three independent experiments. (C) Localization of FLAG tagged DEDD and some of its mutants in transiently transfected HeLa cells 
firmed by transfecting DEDD and its mutants into HeLa cells, indicating that the effects were not restricted to 293T cells (Figure 2C).

\section{A functional DED is required for the proapoptotic activity of DEDD in the nucleus}

All known DED interacting proteins are found in the cytoplasm. Since DEDD required a nuclear localization for cytotoxicity we tested whether a functional DED was required to induce apoptosis. The structure of the DED in FADD has recently been solved by $\mathrm{NMR}^{26}$ Similar to the $\mathrm{DD}$ and the caspase recruitment domain (CARD) the DED comprises 6 amphipathic $\alpha$-helices. One highly conserved amino acid residue was found to be critical for the binding of the FADD DED to the first DED of caspase-8. This phenylalanine residue 25 in FADD corresponds to Phe-47 in DEDD and lies within one of two functionally important lipophilic pockets (I and II in Figure 3A). The other lipophilic pocket was identified at the C-terminal end of the FADD DED, an area highly conserved among DED proteins ${ }^{26}$ (Figure $3 A$ ). To generate a DEDD molecule with a non functional DED we replaced the critical phenylalanine 47 residue by tyrosine or glycine, similar to the mutation of the FADD DED described previously. ${ }^{26} \mathrm{We}$ have recently shown that this DEDD mutant can not bind to a novel DED associated factor (DEDAF) that interacts with DEDD in the nucleus. ${ }^{27}$ In addition, we replaced two leucine residues in pocket II with glycines. We generated these mutants for both full length DEDD and the truncated version of DEDD (N-DEDD) containing only the DED flanked by NLS3 and NLS1 (see Figure 1C). Mutations of the critical residues in the DED resulted in proteins that no longer induced apoptosis (Figure 3B). Furthermore, none of the DED mutants localized to the subnuclear structures seen with wild type DEDD or $\mathrm{N}$ DEDD, suggesting that a functional DED is required for this localization (Figure $3 \mathrm{C}$ ). Interestingly, all three point mutants of N-DEDD (but not of full length DEDD) also showed weak cytoplasmic staining in transfected cells suggesting that a functional DED contributes to the retention of DEDD in the nucleus. Taken together these data suggest the proapoptotic activity of DEDD involves its DED and functions in the nucleus.

\section{DEDD induces caspase- 6 activation in the nucleus}

Overexpression of FADD in 293T cells results in activation of caspase-3 and to a lesser extent caspase-8 (Figure 4A). Most of these active caspases were found in the cytoplasm. Since DEDD requires a nuclear localization to exert its proapoptotic function we tested which caspase was predominantly activated by DEDD and the subcellular localization of that caspase (Figure 4B). In contrast to FADD overexpression which activated cytoplasmic caspase-3, overexpression of DEDD resulted predominantly in the activation of a VEID cleaving activity, which was detected in the nucleus suggesting that caspase- 6 was activated. Five hours after transfection the only detectable caspase activity was that of nuclear caspase-6, suggesting that during apoptosis induction by DEDD nuclear caspase- 6 is the first to be activated. Other caspases such as caspase-8 and 9 were activated $48 \mathrm{~h}$

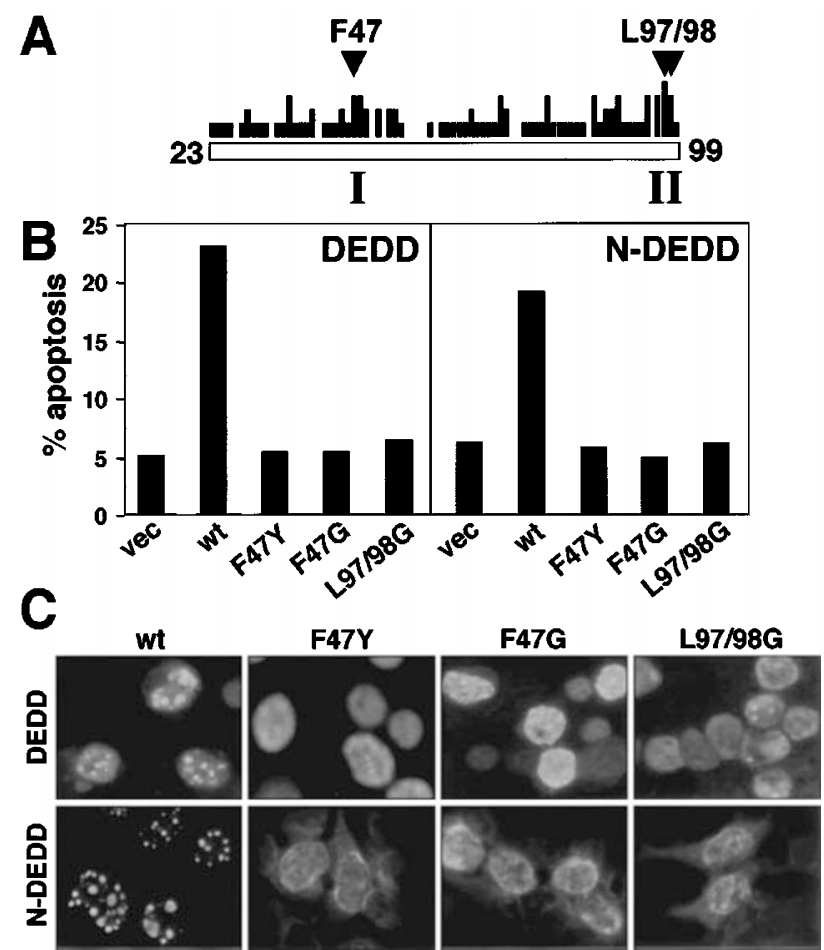

Figure 3 DEDD requires an intact DED to function as a proapoptotic molecule. (A) Positions of high homologies within the DED of DED proteins. The position of two functionally important hydrophobic pockets I and II found in the DED of FADD is shown (according to Eberstadt et al ${ }^{26}$ ). (B) Degree of DNA fragmentation in 293T cells transiently transfected with different DED mutants of DEDD and N-DEDD. The experiment shown is representative of three independent experiments and the results were confirmed by determination of cell death by quantifying changes in the forward/side scatter during the FACS analysis (data not shown). (C) Immunofluorescence microscopy of 293T cells transiently transfected with FLAG-tagged DEDD and N-DEDD and their DED point mutants. Note that all three point mutants of N-DEDD show a significant cytoplasmic staining when compared to wt N-DEDD

after transfection (data not shown), suggesting that they were secondarily activated by DEDD induced apoptosis.

\section{A functional DED in DEDD is required to activate nuclear caspase-6}

To test whether a functional DED was required for activation of caspase- 6 by DEDD in the nucleus we overexpressed DEDD and its F47Y mutant. No caspase-6 activation was detected in nuclei of cells expressing the F47Y mutant (Figure 4C) consistent with our observation that the cytotoxic activity of DEDD was mediated by its DED. To directly demonstrate activation and localization of caspase- 6 in single cells we incubated 293T cells transfected with either DEDD or $\operatorname{DEDD}(\mathrm{F} 47 \mathrm{Y})$ with a cell permeable fluorochrome labeled peptide inhibitor for caspase- $6 .^{28}$ In transfected cells DEDD localized to nucleoli as seen by dark spots in the DAPI stained nuclei (arrow head in Figure 4D) which appeared similar to the nucleolar structures seen in untransfected cells (arrow in Figure 4D). Caspase-6 activity was detected only in the transfected cells which colocalized with DEDD in nucleoli (top right panel in Figure 4D). No caspase-6 positive nuclei were detected in cells expressing DEDD(F47Y) which also did not 

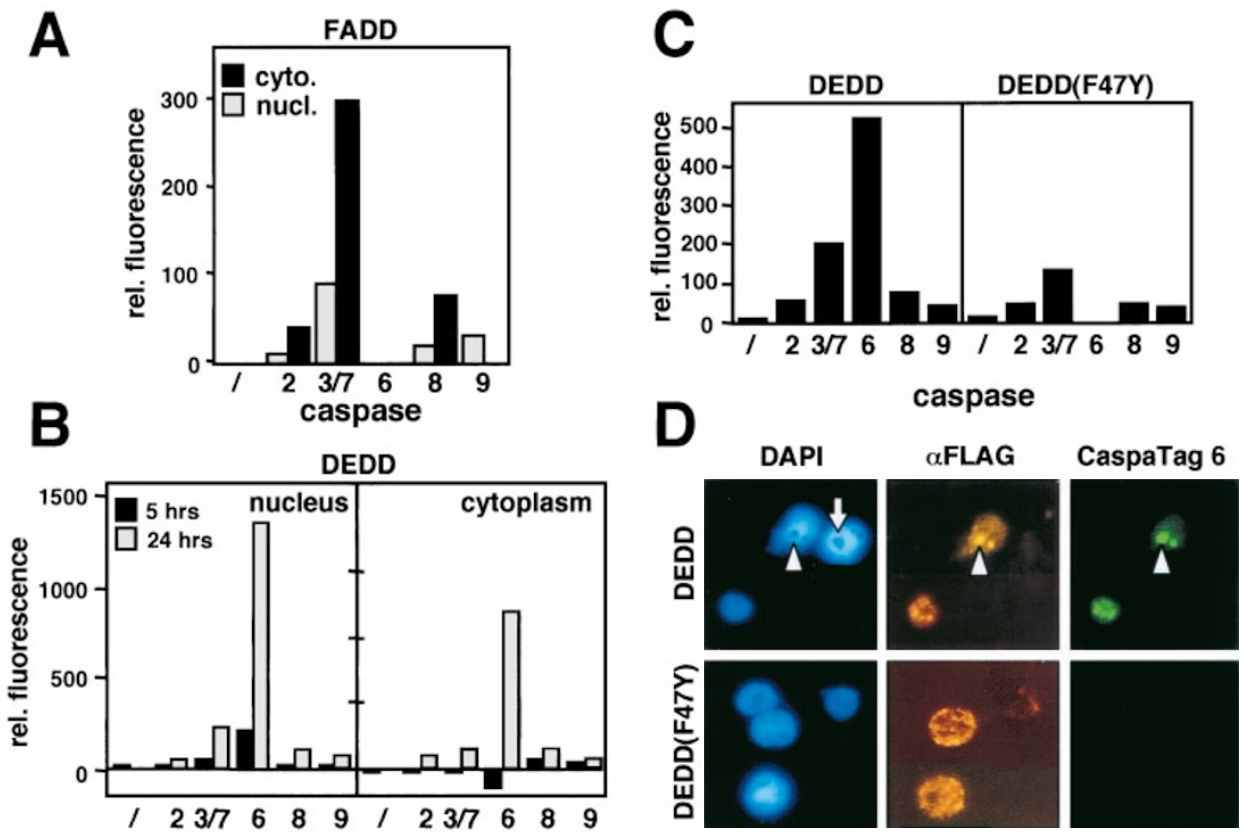

Figure 4 DEDD activates caspase-6 in the nucleus through its DED. (A,B) Caspase activities in cytosolic and nuclear fractions of 293T cells transiently transfected with FADD (A) or DEDD (B) were determined as described in the methods section. We have recently established the specificity of this assay to detect activities of individual caspases. ${ }^{43}$ (C) Activities of different caspases in nuclei of 293T cells transiently transfected with DEDD or DEDD(F47Y). (D) 293T cells were transiently transfected with either $3^{\prime} F L A G-D E D D$ or $3^{\prime} F L A G^{\prime}-D E D D(F 47 Y)$, after $24 \mathrm{~h}$ incubated with the fluorochrome-labeled caspase-6 inhibitor CaspaTag6 and fixed with paraformaldehyde. Cells were stained with DAPI (blue), DEDD expression was detected by staining with an anti-FLAG mAb (green) and labeled active caspase-6 is shown in red. Arrow head: nucleolus containing overexpressed DEDD; Arrow: nucleolus in an untransfected cell

localize to nucleoli (Figure 4D, bottom panels). These data suggest that a functional DED in DEDD is required to activate or recruit caspase-6 in nuleoli.

\section{DEDD specifically inhibits Pol I dependent transcription in nucleoli}

We have previously shown that DEDD has the ability to inhibit transcription of a mini rDNA gene in vitro when added as a GST fusion protein. ${ }^{23}$ However, this assay did not allow us to conclude that DEDD specifically inhibited Pol I dependent transcription. To determine whether DEDD would inhibit rDNA transcription in vivo we transfected DEDD into 293T cells and determined the amount of BrUTP incorporated into nucleoli. When RNA Pol II dependent transcription was inhibited by addition of $\alpha$-amanitin, BrUTP was incorporated into nucleoli precisely colocalizing with endogenous DEDD (Figure 5A, top row). In cells expressing exogenous DEDD, Pol I dependent transcription was completely inhibited (Figure $5 \mathrm{~A}$, arrows in top row), whereas untransfected cells efficiently incorporated BrUTP into their nucleoli. These data indicate that overexpression of DEDD in 293T cells inhibits nucleolar DNA transcription.

Omission of $\alpha$-amanitin, thereby not inhibiting Pol II dependent transcription, resulted in BrU specific staining throughout the nucleus (Figure 5A, bottom row). This transcriptional activity was not affected by overexpression of DEDD, indicating that DEDD acts as a Pol I specific transcriptional inhibitor. All experiments were repeated in the presence of the polycaspase inhibitor zVAD-fmk with identical results (data not shown). The data therefore indicate that the activation of caspases by nuclear DEDD is not involved in its transcriptional repressor activity and that the effects of DEDD on Pol I specific transcription are not simply due to activation of caspases during or subsequent to apoptosis.

DEDD binds DNA with very high affinity. ${ }^{23}$ The unique nuclear function of the DED of DEDD prompted us to test the DNA binding activity of N-DEDD and its activity as a Pol I specific transcriptional repressor (Figure 5B,C). His-NDEDD which comprises the DED flanked by two NLS (see Figure $1 \mathrm{C}$ ) linked to an N-terminal 6 histidine tag, was almost as active as full length DEDD in DNA binding, as shown by agarose gel retardation of migration of restricted $\lambda$ DNA (Figure 5B). ${ }^{23}$ However, while addition of full-length DEDD to DNA had completely prevented it from entering an agarose $\mathrm{gel}^{23} \mathrm{~N}$-DEDD addition resulted in retardation of the migration of the DNA fragments. This indicates that fulllength DEDD has the ability to form higher ordered structures than N-DEDD, suggesting a higher binding affinity of DEDD for DNA or an ability to form aggregates when exposed to DNA. The retardation of the migration of DNA was specific for N-DEDD as it was not observed using His-FADD or BSA as controls (Figure 5B). DNA binding did not depend on a functional DED since N-DEDD(F47Y) bound DNA with similar efficiency (Figure 5B). This experiment also confirmed that the F47Y mutant did not just alter the tertiary structure of the DED in a major way but that it specifically affected only certain functions of DEDD. We then tested N-DEDD's ability to inhibit Pol I 
A
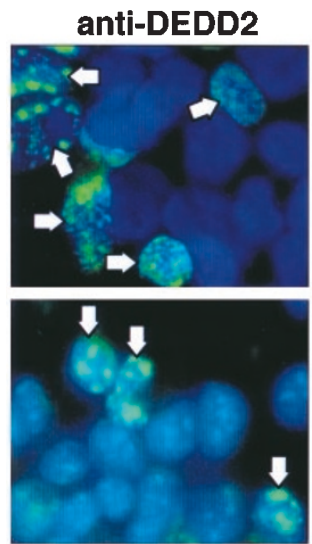

anti-BrdU
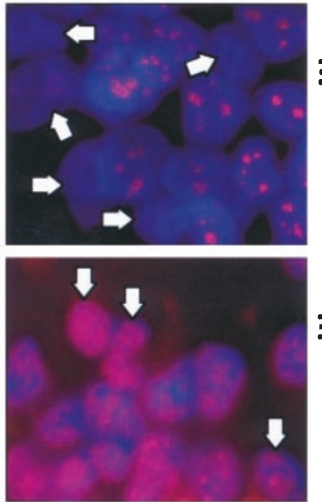

B
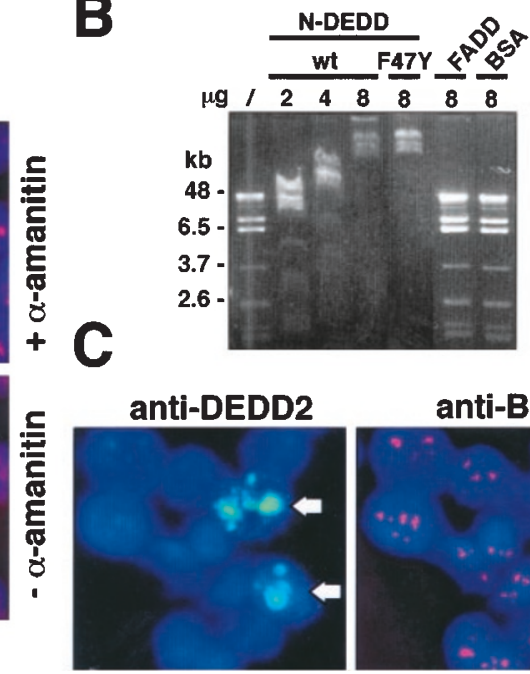

anti-BrdU

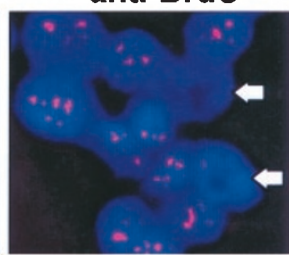

Figure 5 DEDD specifically inhibits Pol I dependent transcription. (A) 293T cells were transiently transfected with pcDNA3-DEDD. Twenty-four hours after transfection transcriptional activity was determined by incorporation of BrUTP for $4 \mathrm{~h}$ either in the presence (upper panels) or absence (lower panels) of $\alpha$-amanitin. Cells were doubled stained with anti-DEDD2 (green) and anti-BrdU (red) and nuclei were visualized by staining with DAPI. Arrows point to cells expressing exogenous DEDD. (B) One $\mu \mathrm{g}$ of restricted phage $\lambda$ DNA was incubated for $10 \mathrm{~min}$ at room temperature with His tagged proteins or BSA at the concentrations indicated, subjected to agarose gel electrophoresis, and visualized by ethidium bromide staining. Lane 1 shows the mobility of DNA without addition of protein. (C) 293T cells were transiently transfected with pcDNA3-N-DEDD. Twenty-four hours after transfection transcriptional activity was determined by incorporation of BrUTP for $4 \mathrm{~h}$ in the presence of $\alpha$-amanitin. Note: this experiment was done in the presence of $50 \mu \mathrm{M}$ zVAD-fmk to exclude effects of caspase activation. Cells were double stained as in C. Arrows point to cells expressing exogenous N-DEDD

dependent transcription. Similar to full-length DEDD, NDEDD inhibited rDNA transcription in vivo in cells treated with $\alpha$-amanitin (Figure $5 \mathrm{C}$ ), suggesting that the location of the transcriptional repressor domain of DEDD coincides with its DED. The DED in DEDD therefore has multiple functions many of which seem to be important in the nucleus.

\section{Endogenous DEDD is localized in the cytoplasm and in the nucleus}

We originally found DEDD to be present in the cytosol of a number of tumor cell lines. ${ }^{23}$ When overexpressed in 293T cells, however, DEDD was mainly localized in the nucleus. Our original anti-DEDD antibody, directed against a peptide located in the proline-rich domain of DEDD (anti-DEDD1) (scheme in Figure 6A), was very sensitive in Western blot experiments, however it could not be used to visualize endogenous DEDD in immunofluorescence experiments (data not shown). ${ }^{23}$ We have generated a second rabbit polyclonal antibody directed against a peptide in the center of the DED domain of DEDD (anti-DEDD2). Similar to antiDEDD1 the new antibody recognizes $37 \mathrm{kDa}$ DEDD in a Western blot when overexpressed in 293T cells (Figure 6A). It also detected DEDD and N-DEDD in transiently transfected 293T cells by immunofluorescence (arrows in Figure 6B). Interestingly, in untransfected cells anti-DEDD2 detected endogenous DEDD in subnuclear structures (arrow heads in Figure 6B) suggesting that endogenous DEDD in 293T cells was in part nuclear. We therefore reexamined whether endogenous DEDD is expressed in the nucleus. We subjected BJAB and HeLa cells to subcellular fractionation and detected DEDD with anti-DEDD1 in Western blot (Figure
$6 C)$. Jurkat $T$ cells were similarly analyzed since we had previously not detected DEDD in the nuclear fraction of these cells (Figure $6 \mathrm{C}$ ). ${ }^{23}$ Consistent with our previous observation DEDD was detected in the nuclear fraction of Jurkat cells only after long exposure (data not shown). Very little DEDD was found in nuclei of BJAB cells (Figure $6 \mathrm{C}$ ), consistent with a weak staining of nuclear DEDD in these cells (data not shown). A small but significant amount of DEDD was detected in the nuclei of HeLa cells (Figure $6 \mathrm{C}$ ). In summary, a small amount of DEDD can be found in the nuclear compartment of all cells tested.

\section{Nuclear DEDD is localized in nucleoli}

To confirm that DEDD can be detected in nuclei of HeLa cells we used the anti-DEDD2 antibody in immunofluorescence microscopy. Some DEDD was found in the cytosol, however a significant amount was also detected in subnuclear structures (Figure 7A). Anti-DEDD2 also detected DEDD in the cytoplasm and the nucleus of 293T (Figure 7A), MCF7 and NTera-2 cells (data not shown). Because the epitope recognized by anti-DEDD2 in cytoplasmic DEDD is not accessible unless cells are stimulated to undergo apoptosis (data not shown) there is a discrepancy between the amounts of DEDD found in the cytosol and the nucleus of all cells by Western blotting and the amounts in these compartments as detected by immunofluorescence microscopy. The data demonstrate that endogenous DEDD can be found in the nucleus.

To identify the subnuclear structures that contained DEDD a commercially available anti-nucleolus antibody was used for costaining with anti-DEDD2 (Figure 7B). Nuclear DEDD was mainly found in nucleoli, supporting our 

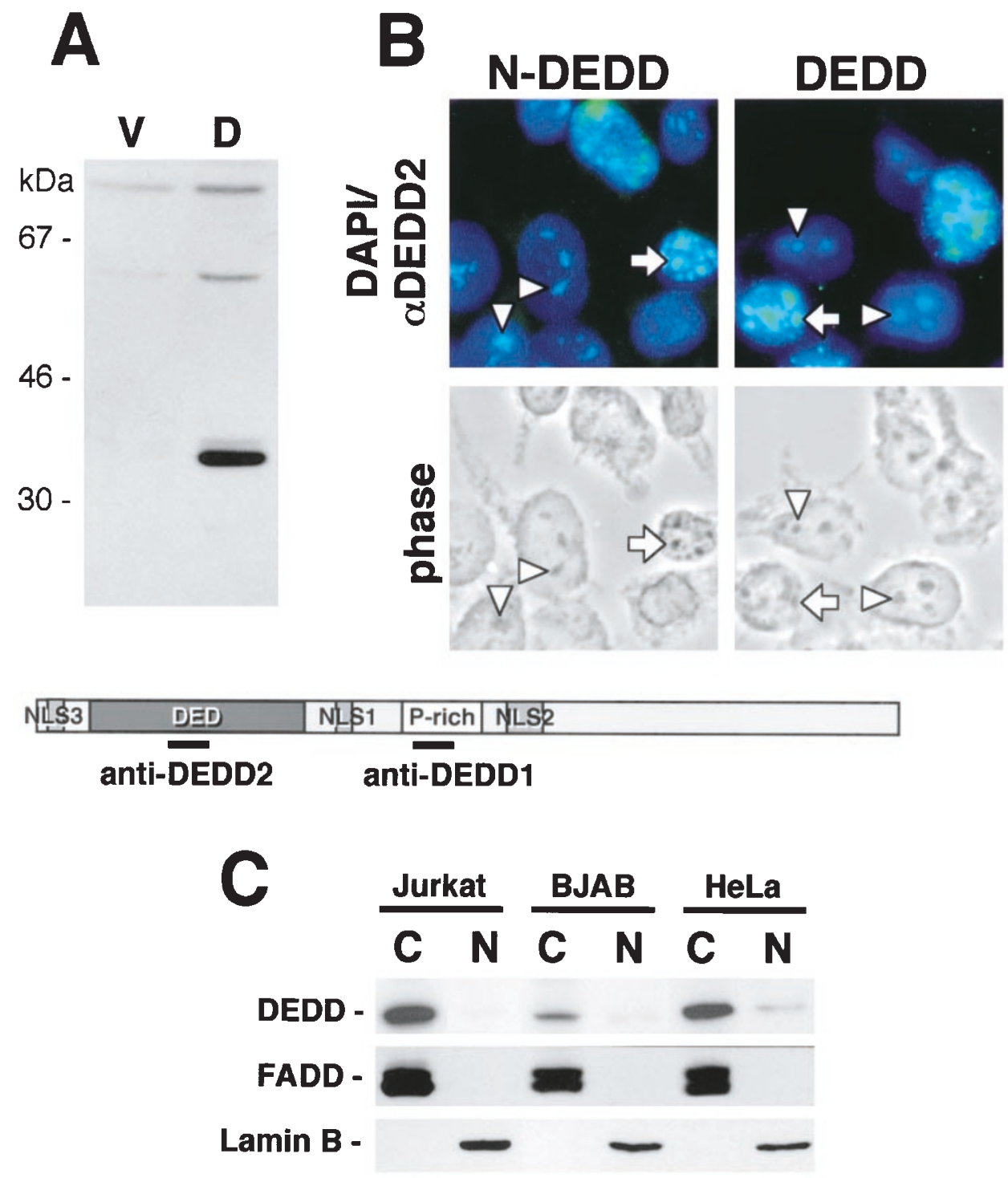

Figure 6 DEDD is expressed in the cytosol and in the nucleus. (A) Western blot of cell extracts of 293T cells transiently transfected with either pcDNA3 or pcDNA3-DEDD using biotinylated anti-DEDD2 and streptavidin-HRPO. Shown below is the localization of the peptides used to generate anti-DEDD1 and antiDEDD2. Peptide DEDD1 is in the proline-rich domain and peptide DEDD2 within the death effector domain of DEDD. (B) Detection of overexpressed N-DEDD and DEDD in nucleoli-like structures of 293T cells transiently transfected with 3'FLAG-N-DEDD or untagged DEDD using the anti-DEDD2 Ab. Arrows point to strongly DEDD/N-DEDD positive structures in nuclei of transfected cells. Arrowheads point to endogenous DEDD in nucleoli of untransfected cells. (C) Western blot detection of DEDD in subcellular fractions of Jurkat, BJAB and HeLa cells. C, cytosol; N, nucleus. Different parts of the same blot were developed with anti-DEDD1, anti-FADD or anti-lamin B

original identification of DEDD as a nucleolar protein. These data were confirmed by costainings of DEDD with PARP, topoisomerase I and the nucleolar protein B23 (data not shown). To confirm the immunofluorescence data and to test whether the DEDD expressed in nucleoli was the same size as the DEDD protein we detected in the cytosol in all cells, we prepared a nucleolus enriched fraction from HeLa cells and detected DEDD in nucleoli by Western blotting (Figure $7 \mathrm{C}$ ). The isolation of nucleoli lead to a specific enrichment of the nucleolus specific marker protein C23 (Figure $7 \mathrm{C}, \mathrm{n}$ ). No enrichment was found for lamin B, which is not present in nucleoli (note that we loaded five times more protein of the nucleolar fraction resulting in lamin $B$ bands of similar intensity in the nuclear $(N)$ and nucleolar ( $n$ ) fractions). The full length $37 \mathrm{kDa}$ DEDD protein was found to be enriched in the nucleolar fraction to a greater extent than even the nucleolar protein C23. These data establish nuclear DEDD as a nucleolar protein in vivo.

\section{Discussion}

Of the many apoptosis signaling pathways, those of the death receptor family are the most well defined. A number of 

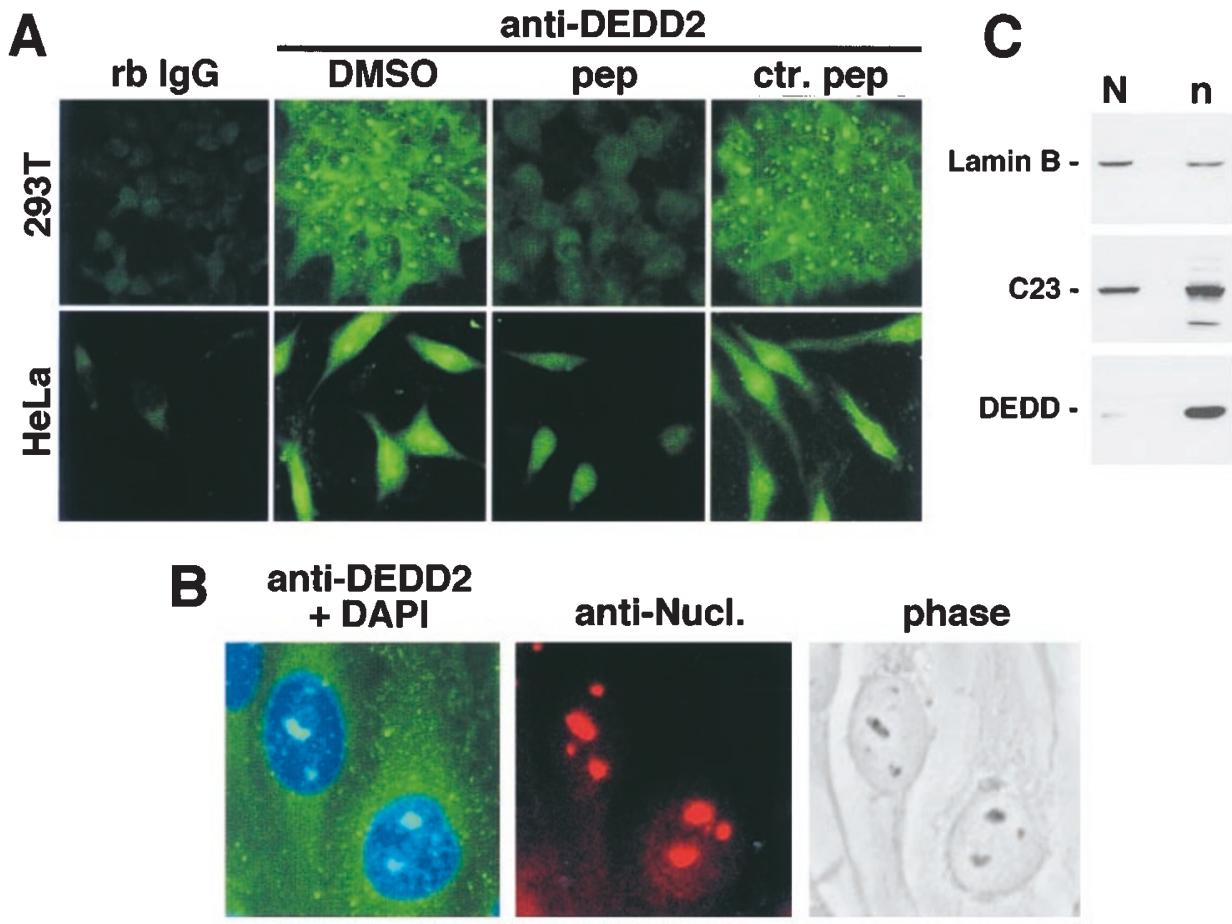

Figure 7 Endogenous nuclear DEDD is a nucleolar protein. (A) Indirect immunofluorescence microscopy of HeLa or 293T cells fixed and stained with either control rabbit $\operatorname{lgG}(\mathrm{rb} \lg \mathrm{G}$ ) or anti-DEDD2 in the presence of either $1 \% \mathrm{DMSO}, 10 \mu \mathrm{M}$ of DEDD2 peptide (pep) or an unrelated control peptide (ctr. pep) and a FITC conjugated goat anti-mouse IgG. (B) costaining for DEDD and nucleoli using the anti-DEDD2 Ab and a commercial anti-nucleolus mAb. Proteins were visualized with a TRITC-conjugated goat anti-mouse IgG (anti-Nucl.) and a FITC conjugated gt anti-rabbit IgG (anti-DEDD2). (C) Extracts of HeLa cells were prepared and fractionated into total nuclear $(\mathrm{N})$ and nucleolar $(\mathrm{n})$ fractions. Ten $\mu \mathrm{g}$ of the nuclear and a $50 \mu \mathrm{g}$ of the nucleolar sample were analyzed by Western blotting using anti-lamin B, anti-C23/nucleolin and anti-DEDD1. Lamin B, C23 and DEDD migrated at 70, 100 and $37 \mathrm{kDa}$, respectively

molecules that are part of the signaling complexes formed at the activated death receptors carry a specialized domain, the DED, for homophilic interactions. All proteins previously identified by sequence comparison containing such a domain were found to be involved in apoptosis signaling. DEDD carries a well conserved DED at its N-terminus. Despite a weak interaction of DEDD with FADD late during apoptosis, ${ }^{23}$ DEDD is not part of the CD95 death-inducing signaling complex and it only weakly interacts with caspase-8 and FADD in vitro. ${ }^{23}$

We originally found overexpressed DEDD in subnuclear structures which we determined to be nucleoli. This was based on the colocalization of exogenous FLAG-tagged DEDD with endogenous UBF. ${ }^{23}$ Using a new anti-DEDD antibody we now demonstrate that endogenous DEDD can be detected in the nucleus where it localizes to nucleoli. This antibody, which was generated against the DED of DEDD, hardly recognizes cytoplasmic DEDD in non apoptosing cells suggesting that this epitope in DEDD's DED is hidden. Cytoplasmic DEDD, however, becomes visible when cells are induced to undergo apoptosis and it tightly associates with intermediate filament proteins in a caspase-3 dependent fashion (unpublished data). Taken together all data suggest that DEDD is not a direct part of the signaling cascade of death receptors but it functions in a more general way downstream in the apoptosis pathway.
During mitosis the various classes of nucleolar proteins distribute to several parts of the cell. The transcriptional apparatus remains assembled with RNA Pol I and its associated transcription factors located in the nucleolar organizer regions (NORs) of chromosomes. ${ }^{29}$ In contrast, the pre-RNA-processing components are found in at least two intracellular sites: the perichromosomal region, where these components surround all chromosomes ${ }^{30}$ and second, large cytoplasmic nucleolus-derived foci. ${ }^{31}$ The nucleolus with all its components reassembles late during telophase. ${ }^{32}$ The cytoplasmic localization and the three functional NLS in DEDD suggest a direct crosstalk between the cytoplasm and the nucleus. The difference between the localization of overexpressed (nuclear) and endogenous (mainly cytosolic) DEDD may be caused by association of DEDD either with itself or with another protein that masks its three NLS. We do not know yet whether or when nucleolar and cytoplasmic DEDD communicate with each other. However, early during mitosis, when nucleoli disassemble, DEDD is found in the cytoplasm and does not colocalize with the segregating chromosomes despite its DNA binding activity (data not shown). ${ }^{23}$ It is also not found in NORs, suggesting that it is not directly part of the transcriptional machinery. It first appears in perichromosomal regions and later during telophase it is found throughout the cytoplasm and does not colocalize with nucleolus-derived foci. When nucleoli reassemble during 
cytokinesis DEDD moves back into nucleoli (data not shown).

Nucleoli have long been viewed as the site of rDNA transcription and assembly of ribosomes. However, it has become increasingly clear that they actively participate in the apoptosis process. Non activated p53 significantly localizes to nucleoli and is believed to monitor sites of active transcriptional activity, ${ }^{33}$ and UBF has been shown to be cleaved by caspases early during apoptosis. ${ }^{34}$ It was demonstrated that UBF moves out of nucleoli during apoptosis whereas other nucleolar protein such as B23 stay within these structures. ${ }^{35}$ This behavior has been interpreted as the result of the cleavage of UBF by caspases and has established UBF as a target that is inactivated early during apoptosis. Furthermore, it was recently shown that during apoptosis UBF localized to fibrogranular threaded bodies whereas fibrillarin, B23 and C23 remained present in micronuclei. ${ }^{36}$ We have observed that the staining for both endogenous DEDD and UBF decreases during staurosporine induced apoptosis in a number of cell lines (data not shown). In vivo DEDD may therefore regulate the transcriptional activity in nucleoli.

Overexpression of FADD results predominantly in activation of caspase- 3 in the cytoplasm. In contrast, DEDD directly or indirectly activates caspase- 6 from within the nucleus, suggesting a very different function for the DED of DEDD than for other DED containing proteins. Active caspase- 6 was found to colocalize with DEDD in nucleoli suggesting a function for caspase- 6 in these subnuclear structures. We do not know yet whether caspase- 6 is activated in nucleoli or whether DEDD recruits caspase- 6 to nucleoli after activation in the cytoplasm. Recently, a novel death domain (DD) containing nuclear protein p84N5 was reported to induce apoptosis from within the nucleus and to also specifically activate nuclear caspase- $6 .{ }^{37}$ Induction of apoptosis by this protein required a functional DD. However, in contrast to p84N5, DEDD does not induce activation of NF- $\kappa \mathrm{B}$ when overexpressed in cells (data not shown). ${ }^{37}$ It is unknown at present what nuclear signaling pathway results in activation of caspase- 6 by either DD or DED containing proteins. However, DEDD seems to act in a different pathway than p84N5 since it possesses a transcriptional inhibitor activity.

DEDD represents the first DED protein that carries NLS and exerts its cytotoxic effect from within the nucleus. When overexpressed FADD and caspase-8 form so called death effector filaments in the cytoplasm that recruit and activate caspase-8. ${ }^{20,21}$ In contrast to these DED proteins, the DED in DEDD seems to function mainly in the nucleus. The DED structure is conserved and mutation of key residues known to disrupt this structure and thereby interactions with other DED binding proteins affects the function of DEDD. It is therefore likely that DEDD engages a nuclear DED binding protein. Recently, a protein was identified that interacts with DEDD in the nucleus. ${ }^{27}$ This DED associated factor (DEDAF) is a good candidate for a DEDD interaction partner since we found that it does not interact with the DED mutant DEDD (F47Y). ${ }^{27}$ Furthermore, DEDAF is as highly conserved between human and mouse as DEDD (98.7\% identity) and both the endogenous protein and stably expressed DEDAF are mainly localized in the nucleus (data not shown). ${ }^{38}$ Future experiments will determine the in vivo role of DEDAF in DEDD signaling. Studying DEDD may provide new insights into a novel nuclear pathway of apoptosis that involves crosstalk between the cytoplasm and nucleoli. Our study shows that the DED in DEDD, although structurally similar to other DEDs, is a multifunctional domain that mainly acts in the nucleus. It binds DNA, induces apoptosis by activating caspase- 6 from within the nucleus and independently of its proapoptotic function can regulate DNA Pol I dependent transcription.

\section{Material and Methods}

\section{Cell lines and reagents}

HeLa, Jurkat and BJAB cells were cultured in RPMI, 293T cells in DMEM in humidified atmosphere $\left(5 \% \mathrm{CO}_{2}\right)$ at $37^{\circ} \mathrm{C}$ supplemented with L-glutamine, $100 \mu \mathrm{g} / \mathrm{ml}$ penicillin and streptomycin, and $10 \%$ heat inactivated fetal calf serum (Sigma). $\alpha$-Amanitin was purchased from Sigma. The polyclonal rabbit anti-DEDD2 antiserum was generated and affinity-purified by Zymed. The serum was raised against the peptide (C)DVIDDHERGLIRNGRD which corresponds to amino acids $51-66$ of the DEDD primary sequence. The plasmids $3^{\prime} F L A G-D E D D$, $3^{\prime}$ FLAG-N-DEDD, 5'FLAG-C-DEDD (all in pcDNA3) ${ }^{23}$ and His$\mathrm{FADD}^{39}$ have been described previously.

\section{Subcellular fractionation and isolation of nucleoli}

For preparation of total cell extracts the cells were resuspended in ice-cold lysis buffer $(250 \mathrm{mM} \mathrm{NaCl}, 50 \mathrm{mM}$ HEPES pH 7.0, $5 \mathrm{mM}$ EDTA, Complete ${ }^{\mathrm{TM}}$ protease inhibitors (Roche)) containing $0.1 \% \mathrm{NP}-40$, tumbled for $1 \mathrm{~h}$ at $4^{\circ} \mathrm{C}$, sonicated and cleared of debris by centrifuging at $14000 \times g$. For preparation of nuclear and cytoplasmic extracts cells were resuspended in ice-cold lysis buffer containing $1 \% \mathrm{NP}-40$, incubated for $15 \mathrm{~min}$ at $4^{\circ} \mathrm{C}$ and centrifuged at $14000 \times g$. The supernatant containing the cytoplasmic fraction was carefully removed, the pellet resuspended in lysis buffer containing $0.1 \% \mathrm{NP}-40$, tumbled for $1 \mathrm{~h}$ at $4{ }^{\circ} \mathrm{C}$, sonicated and cleared of debris by centrifuging at $14000 \times \mathrm{g}$. To prepare nucleoli nuclei were isolated from $5 \times 10^{7}$ HeLa cells as previously described ${ }^{23}$ and nucleoli were prepared as described elsewhere. ${ }^{40}$

\section{Western blotting and peptide competition}

Affinity-purified polyclonal anti-DEDD2 antiserum was biotinylated as previously described. ${ }^{41}$ Proteins were separated by $12.5 \%$ SDSPAGE, transferred to Hybond nitrocellulose membranes (Amersham), blocked with $5 \%$ milk in phosphate-buffered saline with $0.05 \%$ Tween 20 (PBS/Tween) for $1 \mathrm{~h}$, washed with PBS/Tween and incubated for $16 \mathrm{~h}$ at $4^{\circ} \mathrm{C}$ with the following antibodies: affinity-purified polyclonal anti-DEDD1 antiserum ${ }^{23}(1 \mu \mathrm{g} / \mathrm{ml})$, affinity-purified biotinylated polyclonal anti-DEDD2 antiserum $(1 \mu \mathrm{g} / \mathrm{ml})$, goat polyclonal anti-lamin B (M20, Santa Cruz) (1:500), anti-C2/Nucleolin mAb (Santa Cruz) $(0.5 \mu \mathrm{g} / \mathrm{ml})$ and anti-FADD mAb (Transduction Laboratories) $(1 \mu \mathrm{g} / \mathrm{ml})$ all in $5 \%$ dry milk in PBS/Tween. The membranes were washed with PBS/Tween and incubated with either streptavidin-HRP (Pharmingen) $(1: 1000)$ or goat anti-rabbit IgG-HRP (Southern Biotechnology) (1:15 000) in 5\%-milk in PBS/Tween. After washing with PBS/Tween 
the membranes were developed with the $E C L^{\mathrm{TM}}$ Western blotting detection reagents following the manufacturer's protocol (Amersham).

\section{Generation of DEDD mutant constructs}

Using the PolyQuik site-directed mutagenesis kit (Stratagene), standard PCR and cloning techniques the following constructs were generated: 3'-FLAG-N'-DEDD (amino acids 1-98), 5'-FLAG-Exon 2/3 (amino acids 110-193), 5'-FLAG-Exon 4 (amino acids 194-318), 3'FLAG-DEDD $\Delta$ NLS1 (amino acids 104-107 KRRR mutated to KLRL), 3'-FLAG-DEDD- $\triangle$ NLS2 (amino acids 177-181 RKRRK mutated to RILRI), 3'-FLAG-DEDD $\triangle$ NLS3 (amino acids 5-7 KRR mutated to AAA), 3'-FLAG-DEDD $\Delta$ NLS1-3, 3'-FLAG-DEDD(F47Y) and 3'-FLAG$\mathrm{N}-\mathrm{DEDD}(\mathrm{F} 47 \mathrm{Y}$ ) (amino acid $47 \mathrm{~F}$ mutated to $\mathrm{Y}$ ), 3'-FLAGDEDD(F47G) and 3'-FLAG-N-DEDD(F47G) (amino acid $47 \mathrm{~F}$ mutated to G), 3'-FLAG-DEDD(L97/98G) and 3'-FLAG-N-DEDD(L97/98G) (amino acid 97 and $98 \mathrm{~L}$ mutated to $\mathrm{G}$ ), His-N-DEDD, His-N$\operatorname{DEDD}(\mathrm{F} 47 \mathrm{Y})$. All FLAG-tagged constructs were cloned into the pcDNA3 (Invitrogen), all His-tagged constructs into the pRSET A vector (Invitrogen).

\section{Analysis of Exon/Intron-structure}

The human PAC library RPCI1,3-5 and the murine PAC library RPCI21 were screened with the DEDD-cDNA by the Resource Center of the German Human Genome Project (RZPD). Positive clones were confirmed by PCR. Using standard PCR and cloning techniques, different overlapping fragments of the genes were cloned and the genes were fully sequenced.

\section{Immunofluorescence microscopy}

Cells were grown on poly-prep (poly-L-lysine coated) slides (Sigma), washed three times with $\mathrm{PBS} / 1 \mathrm{mM} \mathrm{MgCl}_{2}$ and fixed with methanol:acetone $(1: 1)$ at $-20^{\circ} \mathrm{C}$ for $4 \mathrm{~min}$. The slides were allowed to dry, rehydrated with PBS and incubated for $1-2 \mathrm{~h}$ at roomtemperature with the indicated antibodies: affinity-purified polyclonal anti-DEDD2 antiserum $(8 \mu \mathrm{g} / \mathrm{ml})$, mouse anti-human nucleolus monoclonal antibody (IgG1, Chemicon) $(1: 200)$, anti-FLAG M2 monoclonal antibody (Sigma) $(8 \mu \mathrm{g} / \mathrm{ml})$, mouse monoclonal antibromodeoxyuridine antibody (Roche) $(1 \mu \mathrm{g} / \mathrm{ml})$. For peptide competition, $20 \mu \mathrm{M}$ DEDD2-peptide used for immunization was added to the solution. After washing three times with $\mathrm{PBS} / 1 \mathrm{mM} \mathrm{MgCl}$ the slides were incubated with secondary antibodies (Southern Biotechnology) $(1: 200)$ and DAPI $(2 \mu \mathrm{g} / \mathrm{ml})$ for $1 \mathrm{~h}$ at room temperature. Following the secondary antibodies the slides were again washed three times with $\mathrm{PBS} / 1 \mathrm{mM} \mathrm{MgCl}$ and placed in distilled water and $100 \%$ ethanol for a few seconds. After drying, coverslips were mounted onto the slides using Vectashield mounting medium (Vector Laboratories). To stain HeLa cells at different stages of mitosis exponentially growing HeLa cells on coverslips were identified that showed the typical morphology of mitotic cells. All stainings were analyzed and documented using an Axiovert S100 immunofluorescence microscope equipped with an Axiocam digital camera and software (Zeiss).

\section{Transfection of 293T cells and cytotoxicity assay}

Transfections was performed by using the calcium precipitation method as described previously. ${ }^{23}$ Transfected 293T cells were harvested after $36 \mathrm{~h}$ and DNA fragmentation as a specific measure of apoptosis was quantified as previously described. ${ }^{41}$ The transfection efficiency in all experiments was in the range of $60 \%$.

\section{Run-on transcription}

Cells were grown on poly-prep slides (Sigma), washed with Trisglycerol buffer TB (20 mM Tris- $\mathrm{HCl} \mathrm{pH} 7.4,5 \mathrm{mM} \mathrm{MgCl}_{2}, 25 \%$ glycerol, $0.5 \mathrm{mM}$ PMSF, $0.5 \mathrm{mM}$ EGTA), permeabilized with ice-cold $0.5 \%$ Triton X-100 in TB for 3 min and washed again with TB. Run-on transcription was performed by incubating the slides with run-on transcription buffer $(100 \mathrm{mM} \mathrm{KCl}, 50 \mathrm{mM}$ Tris- $\mathrm{HCl} \mathrm{pH} 7.4,5 \mathrm{mM}$ $\mathrm{MgCl}_{2}, 0.5 \mathrm{mM}$ EGTA, 25\% glycerol, $25 \mu \mathrm{M}$ S-adenosyl-L-methionine, $5 \mathrm{U} / \mathrm{ml}$ RNase-inhibitors, $1 \mathrm{mM}$ PMSF, $0.1 \mathrm{mM}$ ATP, $0.1 \mathrm{mM}$ CTP, $0.1 \mathrm{mM}$ GTP, $0.1 \mathrm{mM}$ BrUTP) with or without $\alpha$-amanitin $(100 \mu \mathrm{g} / \mathrm{ml})$ for $30 \mathrm{~min}$ at room temperature. Subsequently, slides were washed with TB plus $5 \mathrm{U} / \mathrm{ml}$ RNase-inhibitors, fixed with methanol:acetone $(1: 1)$ at $-20^{\circ} \mathrm{C}$ for 4 min and further processed as described above. Staining was done using an anti-BrdU antibody which is crossreactive with BrUTP.

\section{DNA binding assay}

His-N-DEDD and His-FADD recombinant proteins were prepared as previously described. ${ }^{42}$ Two 4 and $8 \mu \mathrm{g}$ protein (His-N-DEDD, HisFADD or BSA) were incubated for 10 min at room temperature with $100 \mathrm{ng}$ digested phage $\lambda$ DNA ( $1: 1$ mixture of $\lambda$ DNA/Eco47l marker 13 and $\lambda$ mix marker 19 from MBI) in $15 \mu$ l of buffer $(40 \mathrm{mM}$ Tris- $\mathrm{HCl}$ $\mathrm{pH} 7.4,6 \mathrm{mM} \mathrm{MgCl} 2,2 \mathrm{mM} \mathrm{CaCl} 2$ ). Formation of DNA-protein complexes was analyzed on $1 \%$ agarose gels.

\section{Caspase activity assay}

Nuclei and cytoplasmic extracts of 293T cells transfected with different DEDD constructs were prepared as described previously. ${ }^{23}$ The fluorogenic caspase activity assay using AFC-labeled peptides (Bachem) resembling the optimal cleavage sequences for caspase-2 (zVDVAD-AFC), caspases 3/7 (zDEVD-AFC), caspase-6 (zVEIDAFC), caspase-8 (zIETD-AFC) and caspase-9 (Ac-LEHD-AFC) was performed as previously described. ${ }^{28}$

\section{Localization of active caspase- 6 in single cells}

Twenty-four hours after transfection, 293T Cells were trypsinized, washed with $\mathrm{PBS} / 1 \mathrm{mM} \mathrm{MgCl}$ and incubated in a small volume of medium containing $1 \times$ solution of CaspaTag 6 (Intergen) for $1 \mathrm{~h}$ at $37^{\circ} \mathrm{C}$. After incubation cells were washed twice with medium, resuspended in medium without FCS and allowed to adhere on polyL-lysine coated slides for $10 \mathrm{~min}$ at $37^{\circ} \mathrm{C}$. The slides were washed three times with PBS/ $1 \mathrm{mM} \mathrm{MgCl} 2$ and the cells were fixed in PBS containing $1 \%$ paraformaldehyde for $30 \mathrm{~min}$ at $4^{\circ} \mathrm{C}$. To block paraformaldehyde, the slides were incubated three times for 3 min in PBS containing $50 \mathrm{mM} \mathrm{NH}_{4} \mathrm{Cl}$ (at room temperature). To permeabilize the cells, the slides were incubated in ice cold PBS containing $0.3 \%$ TX-100 for $1 \mathrm{~min}$ and rinsed with PBS, followed by a 10 min-incubation in a buffer (PBS with $0.01 \%$ saponin, $0.25 \%$ gelatin and $0.02 \% \mathrm{NaN}_{3}$ ) to block unspecific antibody binding. Subsequently slides were incubated for $1-2 \mathrm{~h}$ at room temperature with the antiFLAG monoclonal antibody M2 (Sigma) $(8 \mu \mathrm{g} / \mathrm{ml})$, washed three times with PBS/1 $\mathrm{mM} \mathrm{MgCl}_{2}$ and incubated with a TRITC-labeled goat antimouse IgG secondary antibody (Southern Biotechnology) $(1: 200)$ and DAPI $(2 \mu \mathrm{g} / \mathrm{ml})$ for $1 \mathrm{~h}$ at room temperature. Following the secondary antibody the slides were again washed three times with $\mathrm{PBS} / 1 \mathrm{mM}$ $\mathrm{MgCl}_{2}$ and placed in distilled water and $100 \%$ ethanol for a few seconds. After drying, coverslips were mounted onto the slides using Vectashield mounting medium (Vector Laboratories) and analyzed by fluorescence microscopy. 


\section{Acknowledgements}

$\mathrm{AH}$ Stegh was supported by a stipend from the Boehringer Ingelheim Fonds. We thank Dr M Lenardo and Bryan Barnhart for critically reading the manuscript. The chromosomal localization of murine and human dedd was done with the help of $\operatorname{Dr}$ A Mincheva and A Murmann, respectively.

\section{References}

1. Evan G and Littlewood T (1998) A matter of life and cell death. Science 281: 1317-1322

2. Ashkenazi A and Dixit VM (1998) Death receptors: signaling and modulation. Science 281: $1305-1308$

3. Schulze-Osthoff K, Ferrari D, Los M, Wesselborg S and Peter ME (1998) Apoptosis signaling by death receptors. Eur. J. Biochem. 254: 439-459

4. Wyllie AH, Kerr JF and Currie AR (1980) Cell death: the significance of apoptosis Int. Rev. Cytol. 68: 251-306

5. Earnshaw WC (1995) Nuclear changes in apoptosis. Curr. Opin. Cell Biol. 7: $337-343$

6. Wyllie AH (1980) Glucocorticoid-induced thymocyte apoptosis is associated with endogenous endonuclease activation. Nature 284: 555-556

7. Boldin MP, Varfolomeev EE, Pancer Z, Mett IL, Camonis JH and Wallach DA (1995) A novel protein that interacts with the death domain of Fas/APO1 contains a sequence motif related to the death domain. J. Biol. Chem. 270: 7795-7798

8. Chinnaiyan AM, O'Rourke K, Tewari M and Dixit VM (1995) FADD, a novel death domain-containing protein, interacts with the death domain of Fas and initiates apoptosis. Cell 81: 505-512

9. Boldin MP, Goncharov TM, Goltsev YV and Wallach D (1996) Involvement of $\mathrm{MACH}$, a novel MORT1/FADD-interacting protease, in Fas/APO-1- and TNF receptor-induced cell death. Cell 85: $803-815$

10. Chinnaiyan AM, Tepper C, Lou L, O'Rourke K, Seldin MA, Kischkel F, Hellbardt S, Krammer PH, Peter ME and Dixit VM (1996) FADD/MORT1 is a common mediator of CD95 (Fas/APO-1) and tumor necrosis factor receptor-induced apoptosis. J. Biol. Chem. 271: 4961-4965

11. Muzio M, Chinnaiyan AM, Kischkel FC, O' Rourke K, Shevchenko A, Scaffidi C Zhang M, Ni J, Gentz R, Mann M, Krammer PH, Peter ME and Dixit VM (1996) FLICE, a novel FADD-homologous ICE/CED-3-like protease, is recruited to the CD95 (Fas/APO-1) death-inducing signaling complex. Cell 85: 817-827

12. Fernandes-Alnemri T, Armstrong RC, Krebs J, Srinivasula SM, Wang L, Bullrich F, Fritz LC, Trapani JA, Tomaselli KJ, Litwack G and Alnemri ES (1996) In vitro activation of CPP32 and Mch3 by Mch4, a novel human apoptotic cysteine protease containing two FADD-like domains. Proc. Natl. Acad. Sci. USA 93: 7464-7469

13. Vincenz CA and Dixit VM (1997) Fas-associated death domain protein interleukin-1beta-converting enzyme 2 (FLICE2), an ICE/Ced-3 homologue, is proximally involved in CD95- and p55-mediated death signaling. J. Biol. Chem. 272: $6578-6583$

14. Irmler M, Thome M, Hahne M, Schneider P, Hofmann K, Steiner V, Bodmer JL, Schroter M, Burns K, Mattmann C, Rimoldi D, French LE and Tschopp J (1997) Inhibition of death receptor signals by cellular FLIP. Nature 388: 190-195

15. Scaffidi C, Schmitz I, Krammer PH and Peter ME (1999) The role of c-FLIP in modulation of CD95-induced apoptosis. J. Biol. Chem. 274: 1541-1548

16. Kitsberg D, Formstecher E, Fauquet M, Kubes M, Cordier J, Canton B, Pan G, Rolli M, Glowinski J and Chneiweiss H (1999) Knock-out of the neural death effector domain protein PEA-15 demonstrates that its expression protects astrocytes from TNFalpha-induced apoptosis. J. Neurosci. 19: 8244-8251

17. Ding HF, Lin YL, McGill G, Juo P, Zhu H, Blenis J, Yuan J and Fisher DE (2000) Essential role for caspase-8 in transcription-independent apoptosis triggered by p53. J. Biol. Chem. 275: 38905-38911

18. Bantel H, Engels IH, Voelter W, Schulze-Osthoff K and Wesselborg S (1999) Mistletoe lectin activates caspase-8/FLICE independently of death receptor signaling and enhances anticancer drug-induced apoptosis. Cancer Res. 59: 2083-2090

19. Kawahara A, Ohsawa $Y$, Matsumura H, Uchiyama $Y$ and Nagata S (1998) Caspase-independent cell killing by Fas-associated protein with death domain. J. Cell Biol. 143: 1353-1360
20. Siegel RM, Martin DA, Zheng L, Ng SY, Bertin J, Cohen J and Lenardo MJ (1998) Death-effector filaments: novel cytoplasmic structures that recruit caspases and trigger apoptosis. J. Cell Biol. 141: 1243-1253

21. Perez D and White E (1998) EIB 19K inhibits Fas-mediated apoptosis through FADD-dependent sequestration of FLICE. J. Cell Biol. 141: 1255-1266

22. Lee SW, Ko YG, Bang S, Kim KS and Kim S (2000) Death effector domain of a mammalian apoptosis mediator, FADD, induces bacterial cell death. Mol. Microbiol. 35: $1540-1549$

23. Stegh $A H$, Schickling $O$, Ehret A, Scaffidi $C$, Peterhänsel $C$, Längst $G$, Hoffmann T, Grummt I, Krammer PH and Peter ME (1998) DEDD, a novel death effector domain-containing protein, targeted to the nucleolus. EMBO J. 17: 5974-5986

24. Bieche I, Champeme MH and Lidereau R (1995) Loss and gain of distinct regions of chromosome 1q in primary breast cancer. Clin. Cancer Res. 1: 123-127

25. Shu HB, Halpin DR and Goeddel DV (1997) Casper is a FADD- and caspaserelated inducer of apoptosis. Immunity 6: 751-763

26. Eberstadt M, Huang B, Chen Z, Meadows RP, Ng SC, Zheng L, Lenardo MJ and Fesik SW (1998) NMR structure and mutagenesis of the FADD (Mort1) deatheffector domain. Nature 392: $941-945$

27. Zheng L, Schickling O, Peter ME and Lenardo MJ (2001) The death effector domain-associated factor (DEDAF) plays distinct regulatory roles in the nucleus and cytoplasm. J. Biol. Chem. in press

28. Bedner E, Smolewski P, Amstad P and Darzynkiewicz Z (2000) Activation of caspases measured in situ by binding of fluorochrome-labeled inhibitors of caspases (FLICA): correlation with DNA fragmentation. Exp. Cell. Res. 259: $308-313$

29. Roussel P, Andre C, Comai L and Hernandez-Verdun DJ (1996) The rDNA transcription machinery is assembled during mitosis in active NORs and absent in inactive NORs. Cell. Biol. 133: 235-246

30. Dundr M, Meier UT, Lewis N, Rekosh D, Hammarskjold ML and Olson MO (1997) A class of nonribosomal nucleolar components is located in chromosome periphery and in nucleolus-derived foci during anaphase and telophase. Chromosoma 105: 407-417

31. Dundr M and Olson MO (1998) Partially processed pre-rRNA is preserved in association with processing components in nucleolus-derived foci during mitosis. Mol. Biol. Cell 9: 2407-2422

32. Dundr M, Misteli Tand Olson MO (2000) The dynamics of postmitotic reassembly of the nucleolus. J. Cell. Biol. 150: 433-446

33. Rubbi CP and Milner J (2000) Non-activated p53 co-localizes with sites of transcription within both the nucleoplasm and the nucleolus. Oncogene 19: 85

34. Casiano CA, Martin SJ, Green DR and Tan EM (1996) Selective cleavage of nuclear autoantigens during CD95 (Fas/APO-1)-mediated T cell apoptosis. J. Exp. Med. 184: 765-770

35. Torres-Montaner A, Bolivar J, Astola A, Gimenez-Mas JA, Brieva JA and Valdivia MM (2000) Immunohistochemical detection of ribosomal transcription factor UBF and AgNOR staining identify apoptotic events in neoplastic cells of Hodgkin's disease and in other lymphoid cells. J. Histochem. Cytochem. 48: $1521-1530$

36. Martelli AM, Robuffol, Bortu R, Ochs RL, Luchetti F, Cocco L, Zweyer M, Baregg $R$ and Falcieri $E$ (2000) Behavior of nucleolar proteins during the course of apoptosis in camptothecin-treated HL60 cells. J. Cell Biochem. 78: 264-277

37. Doostzadeh-Cizeron J, Yin S and Goodrich DW (2000) Apoptosis induced by the nuclear death domain protein p84N5 is associated with caspase-6 and NF-kappa B activation. J. Biol. Chem. 275: 25336-25341

38. Garcia E, Marcos-Gutierrez C, del Mar Lorente M, Moreno JC and Vidal M (1999) $\mathrm{RYBP}$, a new repressor protein that interacts with components of the mammalian Polycomb complex, and with the transcription factor YY1. EMBO J. 18: $3404-$ 3418

39. Scaffidi C, Volkland J, Blomberg I, Hoffmann I, KrammerPH and PeterME (2000) Phosphorylation of FADD/MORT1 at serine 194 and association with a 70-kDa cell cycle-regulated protein kinase. J. Immunol. 164: 1236-1242

40. Marciniak RA, Lombard DB, Johnson FB and Guarente L (1998) Nucleolar localization of the Werner syndrome protein in human cells. Proc. Natl. Acad. Sci. USA 95: 6887-6892

41. Peter ME, Hellbardt S, Schwartz-Albiez R, Westendorp MO, Moldenhauer G, Grell Mand Krammer PH(1995) Cell surface sialylation plays a role in modulating sensitivity towards APO-1-mediated apoptotic cell death. Cell Death Differ. 2 $163-171$ 
42. Kischkel FC, Hellbardt S, Behrmann I, Germer M, Pawlita M, Krammer PH and Peter ME (1995) Cytotoxicity-dependent APO-1 (Fas/CD95)-associated proteins form a death-inducing signaling complex (DISC) with the receptor. EMBO J. 14: 5579-5588
43. Stegh AH, Herrmann H, Lampel S, Weisenberger D, Andrä K, Seper M, Wiche G, Krammer PH and Peter ME (2000) Identification of the cytolinker plectin as a major early in vivo substrate for caspase 8 during CD95- and tumor necrosis factor receptor-mediated apoptosis. Mol. Cell. Biol. 20: 5665-5679 